\title{
Evaluation of a community based childhood injury prevention program
}

\author{
Lenna Bablouzian, Ellen S Freedman, Kim E Wolski, Lise E Fried
}

\begin{abstract}
Objectives-This pilot study evaluates the effectiveness of a community based childhood injury prevention program on the reduction of home hazards.

Methods-High risk pregnant women, who were enrolled in a home visiting program that augments existing health and human services, received initial home safety assessments. Clients received education about injury prevention practices, in addition to receiving selected home safety supplies. Fourteen questions from the initial assessment tool were repeated upon discharge from the program. Matched analyses were conducted to evaluate differences from initial assessment to discharge.
\end{abstract}

Results-A significantly larger proportion of homes were assessed as safe at discharge, compared with the initial assessment, for the following hazards: children riding unbuckled in all auto travel, Massachusetts Poison Center sticker on the telephone, outlet plugs in all unused electrical outlets, safety latches on cabinets and drawers, and syrup of ipecac in the home.

Conclusions-A community based childhood injury prevention program providing education and safety supplies to clients significantly reduced four home hazards for which safety supplies were provided. Education and promotion of the proper use of child restraint systems in automobiles significantly reduced a fifth hazard, children riding unbuckled in auto travel. This program appears to reduce the prevalence of home hazards and, therefore, to increase home safety.

(Injury Prevention 1997; 3: 14-16)

Keywords: evaluation; home hazard; home visiting; community based program.

Unintentional injuries constitute a major public health problem, ranking as the fourth leading cause of death in the United States. ${ }^{1}$ Community based interventions have been recommended as effective strategies to reduce injury rates. ${ }^{2} 3$ This paper describes a pilot study to evaluate the effectiveness of a community based home visiting program in Boston for reducing home hazards and increasing home safety.
The Childhood Injury Prevention Progran of the Boston Public Health Commission works to reduce the rate of unintentionat injuries to children through public healt education, distribution of safety supplies, and support for the enforcement of safety regulations. As more than $90 \%$ of all injuries $t \vec{\Theta}$ children under the age of 5 occur in the home a collaboration between the Childhood Injury Prevention Program and the Healthy Bab Program was initiated in 1987.

The Healthy Baby Program, also in the Boston Public Health Commission, is a come munity based, home visiting program that augments the services available to high risf pregnant women and their children in the neighborhoods of Boston with the highesक infant mortality rates. Program clients com气 from a predominantly low income, minoritg population. In 1994, the mean monthly incom $\overrightarrow{\bar{E}}$ of Healthy Baby Program clients was $\$ 614$ an $\$$ the racial/ethnic composition was $67 \%$ black $25 \%$ latina, $5 \%$ white, and $3 \%$ other.

\section{Methods}

The program home visiting staff of publie health nurses and neighborhood health advo cates conduct home safety assessments as pars of their routine home visits. Participanto selected for this pilot study were all Health Baby Program clients. Women are referred to the program based on risk assessments con $₹$ ducted during prenatal care visits at neighborg hood health centers and hospital clinics. standardized tool, The SafeHome Reports. developed by the Massachusetts Departmento of Public Health, was used to conduct the initial home safety assessments (see appendix) Forty four potential home hazards werew assessed in the following six categories: (1) kitchen safety, (2) bathroom safety, (3) chil 9 area safety, (4) general safety, (5) safetos supplies, and (6) safety practices. Sixty eighit per cent of home hazards were assessed b] actual observation or measurement (for exam $\vec{\Phi}$ ple, measurement of hot water temperature्ष्ठ with a thermometer). The remaining hazards were assessed by parent self report (for example, 'does your child ride buckled uQ during all auto travel?'). Upon completion of the initial assessments, nurses and advocate provided education and counseling to clients about injury prevention practices, in addition to dispensing specific safety supplies.

The home visitors also promoted the use of proper child restraint systems in automobiles, 
and made appropriate referrals to a car seat loan program that serves new mothers delivering infants at Boston Medical Center.

To evaluate the impact of the initial home safety assessments, 14 of the original 44 home hazards were reassessed upon discharge of the clients by the nurse or advocate following up the case. These 14 were chosen because seven of the 14 discharge hazards are safety measures regulated by the Massachusetts State Sanitary Code, which defines minimum standards for habitation. ${ }^{5}$ The remaining seven hazards are designated as areas of high priority by the Massachusetts Department of Public Health and the Childhood Injury Prevention Program.

A one group pretest-posttest design was used to evaluate the differences between initial home safety assessment and discharge home safety assessment. McNemar's test for matched pairs of dichotomous data was conducted for each hazard. The analysis of the hazard regarding loose, chipping, or peeling paint was excluded due to a change in the coding of the responses. All analyses were conducted using SAS (the Statistical Analysis System).$^{6}$ This study was conducted between 1 January 1994 and 30 June 1994.

\section{Results}

Results are based on 72 Healthy Baby Program clients for whom both initial home safety assessment and discharge data were available. The mean length of time from initial home safety assessment to discharge was three and one half months.

The 13 analyzed hazards are shown in the table, with the percentage safe at both initial and follow up assessments, the percentage of hazards resolved, and the statistical significance. Eight home hazards did not show a statistically significant change from initial assessment to discharge. On average, $85 \%$ of homes that did not show statistically significant changes were assessed as safe at both initial assessment and discharge, leaving little room for improvement. On the other hand, five of the 13 discharge situations displayed a statistically significant improvement from initial assessment, as shown in the table.

Home hazards with percentage safe at both initial and follow up assessments, percentage resolved, and statistical significance

\begin{tabular}{lll}
\hline Hazard & $\begin{array}{c}\text { \% Safe initial } \\
\text { and follow up }\end{array}$ & \% Resolved \\
\hline 1. Access to windows blocked $(n=53)$ & 75 & 11 \\
2. Children ride buckled in autos $(n=48)$ & 75 & $15^{\star \star}$ \\
3. Electrical cords in safe condition $(n=44)$ & 95 & 4 \\
4. Hall and stairway lighting adequate $(n=51)$ & 92 & 2 \\
5. Massachusetts Poison Center sticker on telephone $(n=50)$ & 54 & $32^{\star \star}$ \\
6. Outlet plugs in all unused electrical outlets $(n=47)$ & 32 & $26^{\star}$ \\
7. Safe hot water temperature $(n=49)$ & 82 & 12 \\
8. Safety latches on cabinets and drawers $(n=46)$ & 37 & $24^{\star \star}$ \\
9. Secure screens on windows $(n=51)$ & 88 & $40^{\star \star \star}$ \\
10. Syrup of ipecac in home $(n=50)$ & 42 & 8 \\
11. Stairs and balconies sturdy $(n=51)$ & 84 & 12 \\
12. Two unobstructed exits $(n=49)$ & 75 & 6 \\
13. Working smoke detectors $(n=49)$ & 86 &
\end{tabular}

Level of significance: ${ }^{\star} 0.01<\mathrm{p}<0.05 ;{ }^{\star \star} 0.001<\mathrm{p}<0.01 ;{ }^{\star \star \star} \mathrm{p}<0.001$.

\section{Discussion}

This evaluation indicates that this program significantly reduced four home hazards for which safety supplies were provided-namely, the Massachusetts Poison Center sticker on the telephone, outlet plugs in all unused electrical outlets, safety latches on cabinets and drawers, and availability of syrup of ipecac, a commercially available, over-the-counter product used to induce vomiting in certain cases of poisoning. A fifth hazard, children riding unbuckled in auto travel, was reduced through education and promotion of the proper use of child restraint systems.

This finding is consistent with the only other study on this subject with a comparable population. Schwarz et al conducted a randomized trial in a low income African-American community in Philadelphia. ${ }^{7}$ The intervention consisted of home inspection and modification, as well as education about injury prevention practices. The results showed a difference between control and intervention homes with respect to safety knowledge and home hazards that required minimal to moderate effort to correct.

This pilot study has several limitations. The intervention was delivered as part of a publicly funded service delivery program. As such, it was unethical to withhold the intervention from eligible participants. Therefore, a control group was not included. However, the Boston Public Health Commission was committed to an evaluation of the program using available data.

Potential selection bias cannot be ruled out due to differential sizes for each hazard assessed. A potential for observer bias exists because the same observer conducted the initial and follow up home assessments. However, as care providers, the nurses and advocates are committed to assisting clients to make necessary home safety improvements. A longer follow up period would be necessary to determine if safety improvements are sustained over time. Finally, generalizability of the results is limited by the characteristics of the sample. The study population comes from predominantly low income communities of color in the inner city.

Ultimately, the goal of the Childhood Injury Prevention Program is to reduce injuries to children. To evaluate the impact of the program on rates of childhood injuries, a large scale, randomized, prospective study will need to be conducted, analyzing injury data from hospital and surveillance records. An examination of the cost effectiveness of the program should be a key component of the design.

Based on these analyses however, this community based childhood injury prevention program appears to reduce the prevalence of home hazards and, therefore, to increase home safety. The program is most effective at reducing home hazards for which safety supplies were provided.

Thanks to the staff of the Healthy Baby Program, whose work made this paper possible, and special thanks to their clients for their program participation. 
1 Public Health Service. Healthy people 2000: national health promotion and disease prevention objectives. Washington, 1990.

2 Baker S. Childhood injuries: the community approach to prevention. F Public Health Policy 1981; 2: 235-46.

3 The National Committee for Injury Prevention and Control. Injury prevention: meeting the challenge. Oxford, UK: Oxford University Press, 1989: 23-4.

4 Gallagher SS, Hinter P, Guyer B. A home injury prevention program for children. Pediatr Clin North Am 1985; 32: 95-111.

5 Commonwealth of Massachusetts. Minimum standards of fitness for human habitation. Chapter II, Massachusetts state sanitary code. (105 CMR 410.000-419.000.)

6 SAS Institute. SAS procedures guide, version 6, third edition. Cary, NC: SAS Institute Inc, 1990.

7 Schwarz DF, Grisso JA, Miles C, Holmes JH, Sutton RL. An injury prevention program in an urban AfricanAmerican community. Am $f$ Public Health 1983; 83: $675-80$

\section{Appendix}

\section{SafeHome Report}

KITCHEN SAFETY

1. Are coffee, hot liquids, and hot foods placed out of your child's reach?

2. Are cleaning supplies stored beyond your child's reach?

3. Are cleaning supplies stored separately from food?

4. Are food treats and other attractive items stored over stove?

5. Are vitamins and medicine stored beyond your child's reach?

6. Do you use extra care when heating food for and around your child?

7. Are knives and other sharp objects kept out of your child's reach?

SAFE

Yes No

Yes No

Yęs No

No Yes

Yes No

Yes No

Yes No

BATHROOM SAFETY

8. Are medicine and vitamins stored beyond your child's reach?

9. Are electrical appliances (radio, hair dryer, space heater) used in your bathroom?

10. Is your child always watched by an adult while in the tub?

$11{ }^{\star} \dagger$ Is your home's hot water adjusted to a safe temperature? (The sanitary code allows a range of $110^{\circ}-130^{\circ}$, we recommend $120^{\circ}$ or less to prevent tap water scalds) Your hot water temperature (Let water run for 3 minutes before testing)

CHILD AREA SAFETY

$12 . \dagger$ Is access to windows blocked so your child can't fall out?

13. Are non-accordian type toddler gates used at the top and bottom of stairs?

14. Does crib mattress fit snugly?

15. Are crib slate $2 \frac{3}{8}$ inches or less apart

16. Does toy chest have a lightweight lid, no lid, or a safe closing mechanism?

$17{ }^{\star}+$ Do windows have screens that are secure?

GENERAL SAFETY

18. ${ }^{\star} \uparrow$ Does your house or apartment have two unobstructed exist (in case of fire or other emergency)?
19. $†$ Are electrical cords - extension and appliance cord - in safe conditions?

20. Are electrical cords beyond your child's reach?

21. Are plants placed out of your child's reach?

22. Are all space heaters approved, in safe condition, and inaccessible to your child?

23. Is your wood burning stove in safe condition and inaccessible to your child?

$24{ }^{\star}+$ Are stairs, protective walls, railings, porches, and balconies sturdy and in good condition?

$25 .{ }^{\star} \dagger$ Are hall and stairway lighting adequate (to prevent falls)?

$26{ }^{\star} \dagger$ Does your house or apartment have any loose, chipping, or peeling paint?

27. Can your child get into the basement?

28. Can your child get into the garage?

29. Are pools on your property or in your neighborhood protected from use by unsupervised children? Yes SAFETY SUPPLIES

$30 .^{\star} \dagger$ Do you have a working smoke detector property placed?

31. $\uparrow$ Do you have a Massachusetts Poison Center phone number sticker on your telephone?

$32 . \dagger$ Do you have syrup of ipecac in your home in case of a poisoning? Yes

33. $\dagger$ Do you have safety latches or locks on cabinets and drawers that are within your child's reach and contain any potentially dangerous items? Yes

34. $\dagger$ Do you have shock stops (plastic outlet plugs) in all unused electrical outlets?

35. Do you have a working fire extinguisher (to put out a small fire or to clear an escape path)?

SAFETY PRACTICES

36. Have you developed and practiced a fire escape plan in your home? Yes

37. Are matches and lighters kept out of your child's reach?

38. If you smoke, do you safely dispose of cigarette butts and matches? Yes

39. Has your child been tested for lead poisoning within the last six months? Yes

40. $\dagger$ Does your child ride buckled up during auto travel?

41. Does your child know how to 'drop, roll, and cool' to put out flames if his or her clothes on fire?

42. Do you always watch your infant while she or he is on a high surface (for example, a changing table)?

43. Do you keep small items and food that can choke your child out of his or her reach?

44. Are pocketbooks with vitamins, birth control pills, cigarettes, matches, jewelry, and calculators (with easy to swallow button batteries) kept out of your child's reach?

^Regulated by Massachusetts State Sanitary Code. †Follow up measure. 